\title{
Minireview \\ ReSETting PP2A tumour suppressor activity in blast crisis and imatinib-resistant chronic myelogenous leukaemia
}

\author{
D Perrotti ${ }^{*, 1}$ and P Neviani' \\ 'Human Cancer Genetics Program, Department of Molecular Virology, Immunology and Medical Genetics, and The Comprehensive Cancer Center, \\ The Ohio State University, Columbus, OH 43210 , USA
}

The deregulated kinase activity of p2I0-BCR/ABL oncoproteins, hallmark of chronic myelogenous leukaemia (CML), induces and sustains the leukaemic phenotype, and contributes to disease progression. Imatinib mesylate, a BCR/ABL kinase inhibitor, is effective in most of chronic phase CML patients. However, a significant percentage of CML patients develop resistance to imatinib and/or still progresses to blast crisis, a disease stage that is often refractory to imatinib therapy. Furthermore, there is compelling evidence indicating that the CML leukaemia stem cell is also resistant to imatinib. Thus, there is still a need for new drugs that, if combined with imatinib, will decrease the rate of relapse, fully overcome imatinib resistance and prevent blastic transformation of CML. We recently reported that the activity of the tumour suppressor protein phosphatase 2A (PP2A) is markedly inhibited in blast crisis CML patient cells and that molecular or pharmacologic re-activation of PP2A phosphatase led to growth suppression, enhanced apoptosis, impaired clonogenic potential and decreased in vivo leukaemogenesis of imatinib-sensitive and -resistant (T3I5I included) CML-BC patient cells and/or $\mathrm{BCR} / \mathrm{ABL}^{+}$myeloid progenitor cell lines. Thus, the combination of PP2A phosphatase-activating and $\mathrm{BCR} / \mathrm{ABL}$ kinase-inhibiting drugs may represent a powerful therapeutic strategy for blast crisis CML patients.

British Journal of Cancer (2006) 95, 775-781. doi: 10.1038/sj.bjc.6603317 www.bjcancer.com

Published online 5 September 2006

(c) 2006 Cancer Research UK

Keywords: PP2A; SET; BCR/ABL; CML; forskolin; leukaemia

The equilibrium between kinase and phosphatase signals is essential for the correct control of normal cell survival, proliferation and differentiation (Hunter, 1995). In fact, aberrant activity of cellular kinases has been detected in many cancers, including leukaemias. Among the different oncogenic kinase-driven neoplasia in which altered protein phosphorylation represents the molecular hallmark of the disease, the p210-BCR/ABL oncoproteins of the chronic myelogenous leukaemia (CML), can be considered the best example of an oncogene with constitutive tyrosine kinase activity (Calabretta and Perrotti, 2004).

\section{CML, BCR/ABL AND IMATINIB}

CML is a clonal disorder of the pluripotent haematopoietic stem cells and is clinically characterised by two distinct stages, a protracted myeloproliferative disorder termed chronic phase (CML-CP) that progresses to a rapidly fatal blast crisis (CML$\mathrm{BC}$ ), which can have either myeloid or lymphoid features (Calabretta and Perrotti, 2004). Hallmark of CML is the presence of the Philadelphia chromosome $\left(\mathrm{Ph}^{1}\right)$, product of the reciprocal translocation between chromosome 9 and chromosome 22, $t(9 ; 22)(q 34 ; q 11)$. The translocation results in the fusion of the $\mathrm{BCR}$ to the $\mathrm{c}-\mathrm{ABL}$ gene. In $\mathrm{CML}$, the $\mathrm{BCR} / \mathrm{ABL}$ fusion gene encodes for a $210 \mathrm{kDa}$ protein designated as $\mathrm{p} 210^{\mathrm{BCR} / \mathrm{ABL}}$. It has been well established that the sole expression of $\mathrm{p} 210-\mathrm{BCR} / \mathrm{ABL}$ is sufficient

*Correspondence: Dr D Perrotti; E-mail: danilo.perrotti@osumc.edu Received 12 April 2006; revised 12 July 2006; accepted 20 July 2006; published online 5 September 2006 for the induction of chronic phase CML, and growing evidence gives to $\mathrm{BCR} / \mathrm{ABL}$ a central role also in CML progression into blast crisis (reviewed by Calabretta and Perrotti 2004). In fact, along with other frequent genetic and molecular abnormalities (e.g. double $\mathrm{Ph}^{1}$ chromosome, 553 inactivation) (Johansson et al, 2002), increased expression and activity of the BCR/ABL oncoprotein is frequently observed during CML disease progression and in blast crisis CML (Elmaagacli et al, 2000; Jamieson et al, 2004; Barnes et al, 2005b), and sustained BCR/ABL expression in myeloid progenitor cell lines induces phenotypic changes (i.e. differentiation arrest) characteristic of CML-BC (Perrotti et al, 2002). The ability of BCR/ABL to induce and sustain the leukaemic phenotype depends on its unrestrained tyrosine kinase activity (reviewed by Calabretta and Perrotti, 2004), which is essential for the recruitment and activation of multiple pathways that transduce oncogenic signals leading to growth factor-independent proliferation, increased survival and altered differentiation (Perrotti et al, 2002) of myeloid precursors. In fact, the pleiotropic effect of BCR/ $\mathrm{ABL}$ transformation is mostly dependent on post-translational modifications (e.g. phosphorylation) of signalling molecules, like those involved in the RAS/MAPK, PI3K/Akt and STATs pathways, which control cell growth, survival and differentiation of haematopoietic cells by modulating the expression and/or activity of downstream effectors (Melo and Deininger, 2004; Perrotti et al, 2005) (Figure 1). In blast crisis, increased expression of the BCR/ $\mathrm{ABL}$ oncoprotein accounts for the block of differentiation, inactivation of factors with tumour suppressor activity and decreased genomic stability of the $\mathrm{Ph}^{1}$ blasts (Perrotti et al, 2002; Skorski, 2002; Trotta et al, 2003; Calabretta and Perrotti, 

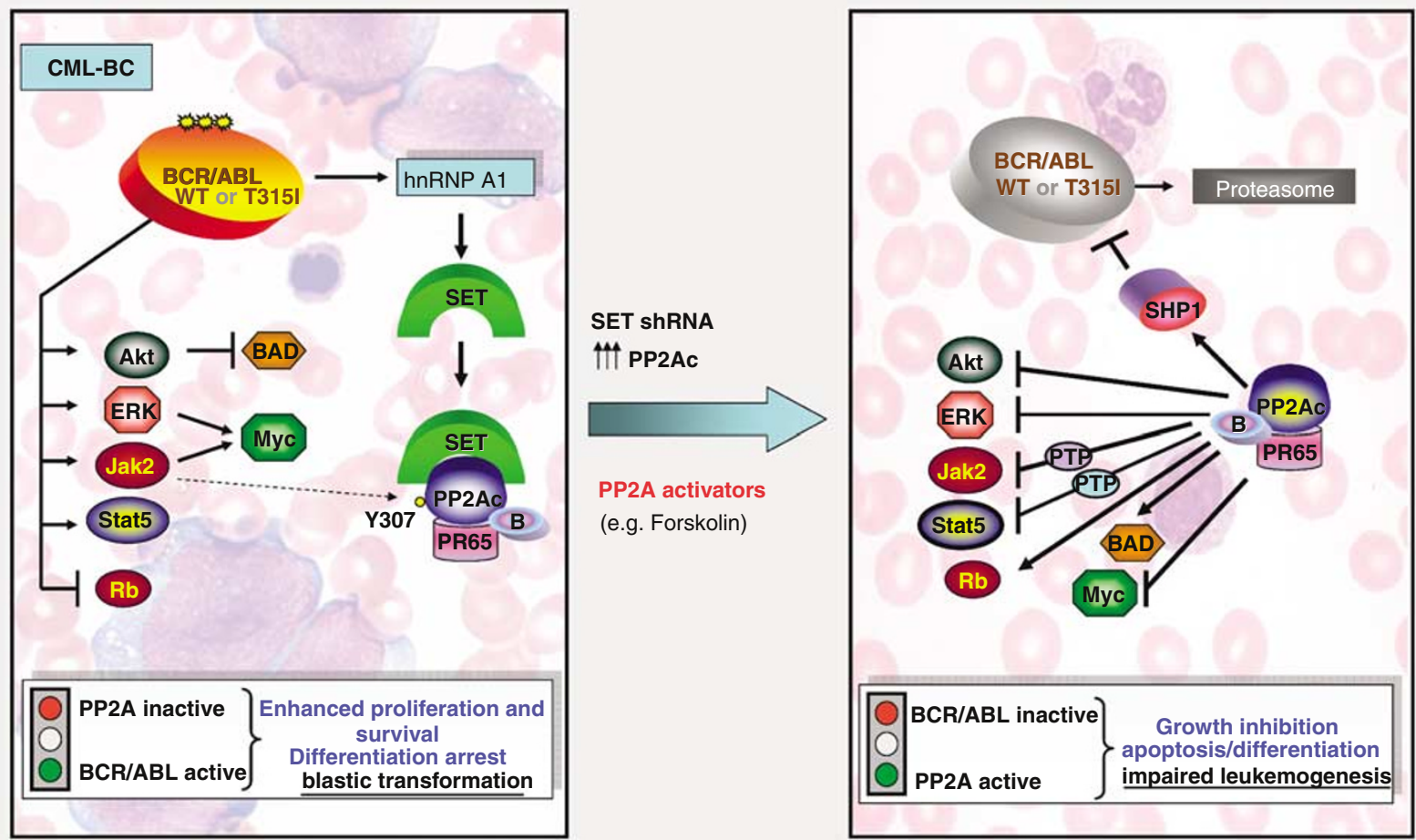

Figure I Molecular Effects of PP2A activation on BCR/ABL and its downstream effectors. (Left) BCR/ABL inhibits PP2A activity by (A) inducing hnRNP Al that, in turn, enhances SET expression, and (B) inducing PP2Ac Y307 phosphorylation. In BCR/ABL ${ }^{+}$myeloid progenitor cells, suppression of PP2A phosphatase activity is required for sustained activation of mitogenic and survival signals, in part, mediated by the indicated BCR/ABL downstream effectors. (Right) Restored PP2A activity, achieved by SET downregulation, PP2Ac overexpression or treatment with PP2A activators (e.g. forskolin or I,9-dideoxyforskolin), impairs in vitro and in vivo wild-type and T3I5I BCR/ABL leukaemogenesis by antagonising the effects of BCR/ABL on its downstream signal transducers and promoting BCR/ABL inactivation and proteasome-dependent degradation.

2004; Neviani et al, 2005). Thus, dependence on BCR/ABL expression is not only a characteristic of CML-CP but also of CML-BC; however, BCR/ABL-independent mechanisms also seem to contribute to disease progression and imatinib resistance in some CML cases (Donato et al, 2003; Dai et al, 2004).

Being the deregulated BCR/ABL kinase activity the cause of CML, targeting its catalytic domain was the most rationale approach for the rational development of small molecules that inhibit ABL kinase activity. Imatinib mesylate (Gleevec, Novartis Basel, Switzerland; STI571), a Kit, Abl and PDGFR inhibitor, induces apoptosis of the $\mathrm{Ph}^{1} \mathrm{CML}$ progenitors by suppressing the ability of $\mathrm{BCR} / \mathrm{ABL}$ to phosphorylate substrates through competitive inhibition at the BCR/ABL ATP binding site (Druker et al, 1996). The development of the BCR/ABL tyrosine kinase inhibitor imatinib mesylate (Gleevec; formerly STI571) as the treatment of choice for chronic phase CML and its remarkable therapeutic effects suggest that blast crisis transition will be postponed for several years in the majority of CML patients (Deininger et al, 2005a; Roy et al, 2006). However, the persistence of BCR/ABL transcripts in a cohort of patients with complete cytogenetic response (Hughes et al, 2003) and the resistance of the primitive CML stem cell to imatinib treatment (Copland et al, 2006) raises the possibility that treatment with imatinib alone might delay but not prevent disease progression. Furthermore, most of the CML patients in the accelerated and blastic phases of the disease are either refractory or develop resistance to imatinib monotherapy (Deininger et al, 2005a). In these CML-BC patients, imatinib resistance often depends on reactivation of $\mathrm{BCR} / \mathrm{ABL}$ tyrosine kinase activity via mechanisms involving BCR/ABL overexpression, gene amplification or mutations that suppress imatinib- mediated kinase inhibition (i.e. E255V and G250E) or disrupt imatinib binding (i.e. T315I) (Shah and Sawyers, 2003). Thus, development of imatinib resistance appears to predispose to blastic transformation. Although new phase 1 clinical trials with the dual Src/Abl inhibitor dasatinib (BMS-354825) and the selective Abl inhibitor AMN107 show encouraging results (O'Hare et al, 2005), as they suppress the activity of most BCR/ABL mutants (except T315I) (O'Hare et al, 2005), in vitro evidence suggests that resistance to these new compounds may develop through mechanisms involving the selection and expansion of $\mathrm{BCR}_{\mathrm{ABL}}{ }^{+}$cell clones carrying the T315I BCR/ABL mutant (Deininger et al, 2005b). Additionally, dasatinib, like imatinib, is not effective in the treatment of CML-BC patients (Talpaz et al, 2006), and in killing the most primitive quiescent CML cells (Copland et al, 2006) and, therefore, it may also be ineffective in preventing disease progression.

The mechanisms responsible for transition of CML chronic phase into blast crisis remain poorly understood, although a reasonable assumption is that the unrestrained activity of $\mathrm{BCR} /$ $\mathrm{ABL}$ in haematopoietic stem/progenitor cells is the primary determinant of disease progression. However, a plausible model of disease progression predicts that increased BCR/ABL expression promotes the secondary molecular and chromosomal changes essential for the expansion of cell clones with increasingly malignant characteristics, and remains crucial for the malignant phenotype even in advanced stages of the disease (Calabretta and Perrotti, 2004). According to this model, CML blast crisis would be expected to occur only in patients with an imatinib-resistant disease or in those developing resistance during treatment. Indeed, a recent study from the GIMEMA Working Party on CML reported 
that the early detection of BCR/ABL mutations in CML chronic phase patients is associated with a greater likelihood of disease progression (Soverini et al, 2005). Interestingly, a direct correlation also seems to exist between levels of BCR/ABL activity and development of imatinib resistance (Schultheis et al, 2005; Barnes et al, 2005a). Thus, there is still a need for new drugs that, if used in combination with the available kinase inhibitors, will decrease the rate of relapse, prevent blastic transformation of CML and, perhaps, overcome imatinib resistance. Therefore, a better understanding of the biology of CML-BC is necessary to identify molecular networks that, if appropriately modulated, will simultaneously affect the function of BCR/ABL and that of multiple signals aberrantly activated in CML-BC.

\section{PROTEIN PHOSPHATASE 2A (PP2A), A PHOSPHATASE WITH TUMOUR SUPPRESSOR ACTIVITY}

Protein phosphatases participate in the normal cell homeostasis by dephosphorylating substrates, therefore providing a negative feedback to signals triggered by kinases. Altered phosphatase and/or kinase activity is often associated to malignant transformation (Hunter, 1995; Blume-Jensen and Hunter, 2001). Hence, some protein phosphatases have been classified as tumour suppressors by virtue of their central role in the regulation of cell growth, survival and/or differentiation (Parsons, 1998; Janssens et al, 2005; Ostman et al, 2006).

PP2A, one of the major cellular serine-threonine phosphatase activity, is a heterotrimeric complex typically consisting of a catalytic subunit $C$, a structural subunit PR65/A, which exists in the isoforms $\alpha$ and $\beta$, and an array of different subunit $\mathrm{B}$ (divided into four families $\mathrm{B}, \mathrm{B}^{\prime}, \mathrm{B}^{\prime \prime}$ and $\mathrm{B}^{\prime \prime \prime}$ ) that confers substrate specificity and target the enzyme to different intracellular location (Janssens and Goris, 2001; Schonthal, 2001). Moreover, the association of the catalytic and structural subunit with some B isoforms determines the tissue- and developmental stage-specific expression patterns to different PP2A complexes (Martens et al, 2004). PP2A is involved in almost all of the cellular processes, including signal-transduction pathways transducing mitogenic and survival signals (e.g. PP2A negatively regulates the RAS/MAPK and the PI3K/Akt pathways), transcriptional and translational regulation, DNA replication and control of cell cycle (Janssens and Goris, 2001; Sontag, 2001).

The ability of PP2A to antagonise cancer development has first been suggested in the late 1980s when it was described as target of the tumour promoter okadaic acid; however, only recently, PP2A received the designation of 'tumour suppressor' (Van Hoof and Goris, 2004; Janssens et al, 2005). In fact, suppression of PP2A activity appears to be a common event in different human neoplasia. For example, genetic alterations of the genes encoding the $\beta$-isoform of the structural subunit $\mathrm{PP} 2 \mathrm{~A}_{\mathrm{A}}$ and some of the regulatory $P$ P2 $A_{B}$ subunits have been found in several types of human cancer (Van Hoof and Goris, 2004; Janssens et al, 2005, and references therein). Moreover, oncogenic viral proteins, such as the SV40 virus small-t antigen, inhibit PP2A activity by interacting with the subunit A of PP2A complexes and displacing various B subunits (Sontag, 2001). Conversely, overexpression of PP2Ac reduces Ha-RAS-induced cellular transformation (Baharians and Schonthal, 1999). As result, loss of PP2A activity leads to constitutive activation and increased stability of protein kinases transducing mitogenic and survival signals (e.g. MAPK and AKT) and protoncogenes (e.g. Myc) (Sontag, 2001; Yuan et al, 2002; Yeh et al, 2004). Furthermore, the PP2A subunit A per se also has been described to be genetically or functionally altered in different types of cancer. Indeed, mutations of PR65/A $\beta$ have been reported in primary lung tumours and in colorectal carcinomas, in which a gene deletion generates a truncated A subunit that is unable to interact with the PP2Ac catalytic subunit (Wang et al, 1998).
Similarly, loss or reduced expression of PR65 has been detected in human gliomas and breast cancer cell lines (Colella et al, 2001; Suzuki and Takahashi, 2003). Accordingly, in immortalised but not tumorigenic cells, expression of PR65/A $\alpha$ mutants defective in binding to other PP2A subunits partially suppressed endogenous $\mathrm{PP} 2 \mathrm{~A}-\mathrm{A} \alpha$ expression, activated the AKT pathway and promoted tumour formation in immunodeficient mice (Chen et al, 2005b). Thus, mutations of the PR65/A subunits might contribute to cancer development by altering the PP2A multimeric composition and, therefore, its phosphatase activity. Alterations in the quaternary structure of PP2A also appears to have a crucial function in cells transformation and tumour development, as different $B$ subunits have been found either aberrantly expressed in human cancers or displaced by the interaction of PR65/A with the SV40 small-t antigen, and by mutations of the PP2A A subunits (Janssens et al, 2005). For example, the B56 $\gamma$ subunit is highly expressed in numerous human malignant melanoma cells compared to normal epidermal melanocytes (Francia et al, 1999). Importantly, B56 $\gamma$ participates also in the regulation of the Wnt/ $\beta$-catenin signalling, a pathway important in the control of cell proliferation and self-renewal of the cancer stem cell. In fact, B56 $\gamma$ directly interacts with APC in the $\beta$-catenin/axin/GSK-3 $\beta$ complex and induces $\beta$-catenin inactivation/degradation (Seeling et al, 1999). Moreover, the catalytic subunit of PP2A has been found associated to axin (Li et al, 2001), suggesting that PP2A:B56 is part of the $\beta$-catenin degradation complex.

In transformed cells, inactivation of PP2A phosphatase and, therefore, loss of its tumour suppressor activity may not only be a consequence of genetic alterations (i.e. mutations) and/or aberrant expression of a specific PP2A subunit, but it could also derive from aberrant activation of signal-transduction pathways leading to post-translational modifications of the PP2A catalytic subunits and/or increased expression of molecules that act as general physiological inhibitors of PP2A phosphatase activity (Janssens and Goris, 2001). In fact, activation of Jak2 (Yokoyama et al, 2001) and/or src (Chen et al, 1992) kinases results in the suppression of PP2A phosphatase activity through a mechanism that involves the phosphorylation of the PP2Ac subunits on tyrosine 307. Likewise, expression of pp32 (I1PP2A) and SET (I2PP2A), two potent physiologic PP2A inhibitors, suppresses the phosphatase activity of all holoenzyme forms of PP2A, most likely through direct binding to the PP2A catalytic subunit (Li et al, 1996; Janssens and Goris, 2001). Interestingly, SET (also known as I2PP2A, IGAAD or TAF-I $\beta$ ) is a nucleus/cytoplasm-localised phosphoprotein overexpressed in solid tumours and leukaemias (Fornerod et al, 1995; Carlson et al, 1998). In addition to its activity as an inhibitor of PP2A, SET is also a potent inhibitor of the tumour suppressor NM23-H1 (Fan et al, 2003). Notably, SET was described as part of a fusion gene with the nucleopore complex protein CAN in a patient with $\mathrm{t}(6 ; 9)(\mathrm{p} 23 ; \mathrm{q} 34)$ acute myeloid leukaemia (AML) (Adachi et al, 1994), and it was found associated with the oncoprotein Mll (ALL1, HRX) in leukaemic cell lines (Adler et al, 1997). Thus, it is intuitive that genetic (mutations in the gene encoding a specific PP2A subunits) or functional (e.g. PP2Ac ${ }^{\mathrm{Y} 307}$ phosphorylation, SET overexpression) inactivation of $\mathrm{PP} 2 \mathrm{~A}$ may represent a step required for cancer development and/or progression. Indeed, the importance of the SET/PP2A interplay in cancer has been recently investigated in chronic myelogenous leukaemia in which a SETmediated inhibition of PP2A phosphatase activity is distinctively occurring in patients with blast crisis CML (Neviani et al, 2005).

\section{BCR/ABL AND PP2A: THE YIN AND YANG OF BLAST CRISIS CML}

Although the mechanisms responsible for CML disease progression are still largely unclear, growing evidence suggests that the phenotype of CML-BC cells depends on the unrestrained activity of 
BCR/ABL and on the genetic or functional inactivation of genes with tumour suppressor activity (Calabretta and Perrotti, 2004). Moreover, altered mRNA metabolism appears to play a pivotal role in blast crisis CML, as mRNA processing, export and translation of specific mRNAs controlling survival and differentiation of myeloid progenitors (e.g. Bcl-X $\mathrm{L}, \mathrm{GCSFR}, \mathrm{C} / \mathrm{EBP} \alpha$ and $\beta, \mathrm{MDM} 2$ and MYC) are aberrantly regulated by increased $\mathrm{BCR} / \mathrm{ABL}$ expression through the activity of specific mRNA binding proteins (e.g. TLS/FUS, hnRNP A1, hnRNP E2, La, hnRNP K and CUGBP1) (Perrotti et al, 1998; Iervolino et al, 2002; Perrotti et al, 2002; Trotta et al, 2003; Guerzoni et al, 2006; Notari et al, 2006). Specifically, the mRNA export activity of hnRNP A1, an RNAbinding protein overexpressed in CML-BC, is required for cytokine-independent proliferation, survival and tumorigenesis of acute phase CML blasts and BCR/ABL-expressing myeloid progenitor cell lines (Iervolino et al, 2002). By Ribonomics (Tenenbaum et al, 2002), we identified SET as a novel BCR/ABL target whose mRNA is specifically associated with hnRNP A1 (Figure 1) in $\mathrm{Ph}^{1} \mathrm{~K} 562$ cells (Neviani et al, 2005).

\section{The SET/PP2A interplay in CML}

SET expression is modestly affected in CML-CP ${ }^{\mathrm{CD} 34+}$ progenitors, but markedly upregulated in myeloid CML-BC ${ }^{\mathrm{CD} 34+}$ cells in which it correlates with loss of PP2A phosphatase activity (Neviani et al, 2005). Interestingly, PP2A inactivation is a direct consequence of increased expression of SET (Figure 1), which is induced by BCR/ $\mathrm{ABL}$ in a dose- and kinase-dependent manner and, like BCR/ABL, progressively increases during transition to blast crisis (Neviani et al, 2005). In fact, imatinib treatment and SET downregulation restored PP2A activity back to normal levels. Interestingly, a portion of PP2Ac is phosphorylated on tyrosine 307 in BCR/ABLexpressing cells, and PP2A ${ }^{\text {TYR307 }}$ levels decreases upon SET downregulation or inhibition of BCR/ABL activity (Neviani et al, 2005). Thus, it is possible that BCR/ABL also affects the ability of PP2A to reactivate itself by autodephosphorylation (Chen et al, 1992) and/or that the SET/PP2A association favours the recruitment of a BCR/ABL-activated tyrosine kinase, which inhibits PP2A through phosphorylation of the PP2Ac tyrosine 307. Alternatively, SET overexpression and src and/or Jak2 activity might independently contribute to PP2A inactivation in BCR/ABL cells (Figure 1). Moreover, the PP2A subunit PR65/A, which is also overexpressed in $\mathrm{BCR} / \mathrm{ABL}^{+}$cells, may also contribute to $\mathrm{PP} 2 \mathrm{~A}$ inactivation, as PR65/A overexpression could sequester the catalytic or variable subunits or act as a PP2Ac inhibitor (Kamibayashi et al, 1992; Wera et al, 1995). Interestingly, it was recently reported that hnRNP A2, an hnRNP with high sequence, structure and function similarity with hnRNP A1, inhibits PP2A activity upon interaction with SET (Vera et al, 2006). Because also hnRNP A2 expression is induced by BCR/ABL (our unpublished observation), the hnRNP A2/SET-dependent inhibition of PP2A may represent another mechanism whereby BCR/ABL induces the loss of PP2A function in CML-BC.

\section{Adverse molecular effects of BCR/ABL and PP2A}

As reported above, the tumour-suppressing activity of PP2A depends on its ability to dephosphorylate several factors regulating cell cycle progression, proliferation, survival and differentiation (Sontag, 2001). Remarkably, several targets are shared by BCR/ $\mathrm{ABL}$ kinase and PP2A phosphatase. Among these, expression and/ or activity of the PP2A targets Myc, STAT5, MAPK, Akt, BAD and $\mathrm{Rb}$ (Neviani et al, 2005, and references therein) are either essential for BCR/ABL leukaemogenesis or have been found altered in CMLBC (Calabretta and Perrotti, 2004, and references therein). In BCR/ ABL-expressing myeloid progenitor 32Dcl3 cells, inhibition of SET expression and, to a greater extent, forced expression of PP2Ac led to inhibition of MAPK, STAT5 and Akt phosphorylation, decreased Myc expression and increased levels of proapoptotic BAD (Neviani et al, 2005) (Figure 1). Since ectopic SET expression antagonised the effects of exogenous PP2A, it is possible that, in CML-BC progenitors, SET-dependent suppression of PP2A activity represents one of the main mechanisms used by BCR/ABL to prevent inactivation of mitogenic and survival signals required for its leukaemogenic activity. The importance of loss of PP2A activity for CML disease progression is also supported by the ability of $\mathrm{PP} 2 \mathrm{~A}$ to induce $\mathrm{Rb}$ dephosphorylation (Avni et al, 2003) and suppress Jak2 kinase, which was found activated in CML-BC (Xie et al, 2002).

\section{BCR/ABL as target of PP2A activity: role of SHP-1}

In imatinib-sensitive and -resistant (T315I included) BCR/ABL cell lines and in $\mathrm{CML}-\mathrm{BC} \mathrm{C}^{\mathrm{CD} 34+}$ patient cells, restoration of PP2A phosphates activity, achieved either by using chemical PP2A activators (e.g. forskolin; Feschenko et al, 2002) or by interfering with the SET/PP2A interplay (i.e. PP2Ac overexpression, SET knockdown), promotes $\mathrm{BCR} / \mathrm{ABL}$ tyrosine dephosphorylation (inactivation) which, in turn, trigger its proteasome-dependent degradation (Neviani et al, 2005). The ability of PP2A to impair activity and expression of oncogenic tyrosine kinases is not unprecedented; in fact, $\mathrm{PP} 2 \mathrm{~A}$ induces inactivation and promotes proteolysis of src kinase (Yokoyama and Miller, 2001). Mechanistically, BCR/ABL proteolysis appears to depend on the PP2Ainduced activation of the tumour suppressor SHP-1 tyrosine phosphatase and on the coexistence of BCR/ABL, PP2A and SHP-1 in the same multiprotein complex (Neviani et al, 2005) (Figure 1). In fact, increased cytokine-independent clonogenic potential and inability of PP2A to promote BCR/ABL degradation was observed in BCR/ABL-transduced SHP-1-decifient CD34 ${ }^{+}$/lineage-negative marrow myeloid progenitors cells (Neviani et al, 2005). Interestingly, BCR/ABL dephosphorylation has been also observed in K562 cells overexpressing tyrosine phosphatase PTP1B (LaMontagne et al, 1998). Although ectopic PTP1B expression impairs clonogenicity and tumorigenesis of p210-BCR/ABL-transformed Rat-1 fibroblasts and induces K562 erythroid maturation (LaMontagne et al, 1998); it is still unclear why PTP1B expression is increased in BCR/ABL-expressing cells (LaMontagne et al, 1998) and whether PTP1B activity is altered in primary CML progenitors or changed during disease progression.

The involvement of SHP-1 in the PP2A-induced negative regulation of $\mathrm{BCR} / \mathrm{ABL}$ kinase activity and expression is also supported by the fact that SHP-1 associates with BCR/ABL and its tyrosine phosphatase activity counteracts BCR/ABL leukaemogenic potential (Liedtke et al, 1998; Lim et al, 2000). Accordingly, expression of SHP-1 is diminished in most of leukaemias and lymphomas, SHP-1 downregulation leads to abnormal cell growth and SHP-1 activity is suppressed by different oncogenic tyrosine kinases (e.g. FLT3/ITD and JAK) (Wu et al, 2003; Chen et al, 2005a). Thus, functional inactivation of PP2A by increased BCR/ $A B L$ kinase activity seems to be required for the transduction of aberrant mitogenic, survival and antidifferentiation signals, and for the post-translational enhancement of $\mathrm{BCR} / \mathrm{ABL}$ expression and oncogenic activity in CML-BC $\mathrm{CD}^{\mathrm{C}}+$ marrow myeloid progenitors (Figure 1).

\section{Restoration of PP2A activity impairs BCR/ABL leukaemogenesis: therapeutic effects of the PP2A activator forskolin}

Consistent with the negative effects of PP2A on BCR/ABL expression and function, restoration of $\mathrm{PP} 2 \mathrm{~A}$ activity back to normal levels via SET downregulation, PP2Ac overexpression or treatment with the potent PP2A activator forskolin (Feschenko et al, 2002) or with 1,9-dideoxy-forskolin (forskolin derivative that lacks adenylate cyclase-cAMP- (Seamon and Daly, 1981) activating 
function) induces marked apoptosis, reduces proliferation, impairs colony formation, inhibits tumorigenesis and restores differentiation of patient-derived myeloid CML-BC ${ }^{\mathrm{CD} 34}+$ cells and/or BCR/ ABL-transformed cell lines, regardless of their degree of sensitivity to imatinib (Neviani et al, 2005). Notably, the imatinib-, AMN107and dasatinib-resistant $\mathrm{T} 315 \mathrm{I} \mathrm{BCR/ \textrm {ABL } ^ { + }}$ cells are also sensitive to PP2A activation (Neviani et al, 2005). Remarkably, forskolin but not 1,9-dideoxy-forskolin delayed proliferation of CD34 + normal marrow cells without inducing either apoptosis or PP2A activity.

Consistent with the in vitro effects of restoration of PP2A activity, in vivo administration of forskolin and/or 1,9-dideoxy forskolin severely impacted and efficiently modulated the development of wild-type and T315I BCR/ABL-induced acute leukaemia-like disease process in immunocompromised mice (Neviani et al, 2005).

Forskolin, a diterpene extracted from the roots of Coleus forskohlii, was primarily and extensively studied and used in rodents and humans for its adenylate cyclase-activating functions and, more recently, for its ability to activate PP2A. Although the molecular mechanism underlying PP2A activation by forskolin (Feschenko et al, 2002) in BCR/ABL-transformed cells is still largely unclear, it seems that it does not depend on increased cAMP or PKA activation (Neviani et al, 2005).

Clinical trials demonstrated the low toxicity of the water-soluble forskolin in the treatment of patients with cardiac dysfunction or bronchospasm (Wajima et al, 2003; Kikura et al, 2004). Furthermore, the use of forskolin as an antileukaemogenic agent is not unprecedented, as it inhibits growth and/or induces apoptosis of different types of leukaemic cells in vitro (Laneuville et al, 1992; Moon and Lerner, 2003). However, all of these studies were all focused on assessing the importance of cAMP in leukaemogenesis, as they were undertaken when the property of forskolin as PP2A activator was still unknown.

The in vivo forskolin and 1,9-dideoxy forskolin antileukaemic activity and the low toxicity are consistent with the long elimination half-life assessed in healthy individuals and with the absence of toxicity in mice treated with these compounds (Kikura et al, 2004; Neviani et al, 2005). Furthermore, the safety and therapeutic effects of these diterpenes are also suggested by the prolonged survival of SCID mice transplanted with wild-type or
T315I BCR/ABL cells (50\% of mice were alive after 25 weeks of treatment while untreated leukaemic mice died within 5 weeks), and by the lack of signs of toxicity or leukaemia after administration of these compound for 18 (Neviani et al, 2005) and 25 (our unpublished data) weeks at 4 and $8 \mathrm{mg} \mathrm{kg}^{-1}$ week ${ }^{-1}$.

Although the ability of forskolin to prevent tumour colonisation and metastasis was reported previously (Agarwal and Parks, 1983), our work for the first time underscores the therapeutic relevance of PP2A-activating drugs in cancer by specifically indicating that treatment of leukaemic mice with forskolin or 1,9-dideoxy forskolin remarkably prolongs the lifespan and decreases the leukaemia burden to a point in which no $\mathrm{BCR} / \mathrm{ABL}^{+}$cells are detected in peripheral blood of treated animals (Neviani et al, 2005).

\section{CONCLUSIONS}

Because of the central role of PP2A in the regulation of cell growth, survival and differentiation, it is clear that its loss-of-function contributes to tumour development and progression. Moreover, the knowledge that functional inactivation of PP2A tumour suppressor activity occurs in myeloid blast crisis CML through the effect BCR/ABL on SET expression, and that re-establishment of normal PP2A activity antagonises both in vitro and in vivo BCR/ ABL leukaemogenesis (see Figure 1), highlights the importance of incorporating PP2A activating drugs (e.g. forskolin) in the current therapeutic protocols for blast crisis and imatinib-resistant (T315I included) CML. In particular, the association of imatinib or new ABL-kinase inhibitors with drugs that enhances PP2A phosphatase activity may represent a successful therapeutic strategy for CML blast crisis patients that are nonresponsive or develop resistance to imatinib and, perhaps, for those patients with Ph1 ALL.

\section{ACKNOWLEDGEMENTS}

This work was supported by the National Cancer Institute CA095512 and the United States Army, Chronic Myelogenous Leukaemia (CML) Research Program DAMD17-03-1-0184.

\section{REFERENCES}

Adachi Y, Pavlakis GN, Copeland TD (1994) Identification and characterization of SET, a nuclear phosphoprotein encoded by the translocation break point in acute undifferentiated leukemia. J Biol Chem 269: $2258-2262$

Adler HT, Nallaseth FS, Walter G, Tkachuk DC (1997) HRX leukemic fusion proteins form a heterocomplex with the leukemia-associated protein SET and protein phosphatase 2A. J Biol Chem 272: 28407-28414

Agarwal KC, Parks Jr RE (1983) Forskolin: a potential antimetastatic agent. Int J Cancer 32: $801-804$

Avni D, Yang H, Martelli F, Hofmann F, ElShamy WM, Ganesan S, Scully R, Livingston DM (2003) Active localization of the retinoblastoma protein in chromatin and its response to S phase DNA damage. Mol Cell 12: $735-746$

Baharians Z, Schonthal AH (1999) Reduction of Ha-ras-induced cellular transformation by elevated expression of protein phosphatase type $2 \mathrm{~A}$. Mol Carcinogen 24: 246-254

Barnes DJ, Palaiologou D, Panousopoulou E, Schultheis B, Yong AS, Wong A, Pattacini L, Goldman JM, Melo JV (2005a) Bcr-Abl expression levels determine the rate of development of resistance to imatinib mesylate in chronic myeloid leukemia. Cancer Res 65: 8912-8919

Barnes DJ, Schultheis B, Adedeji S, Melo JV (2005b) Dose-dependent effects of Bcr-Abl in cell line models of different stages of chronic myeloid leukemia. Oncogene

Blume-Jensen P, Hunter T (2001) Oncogenic kinase signalling. Nature 411: $355-365$
Calabretta B, Perrotti D (2004) The biology of CML blast crisis. Blood 103: $4010-4022$

Carlson SG, Eng E, Kim EG, Perlman EJ, Copeland TD, Ballermann BJ (1998) Expression of SET, an inhibitor of protein phosphatase 2A, in renal development and Wilms' tumor. J Am Soc Nephrol 9: 1873-1880

Chen J, Martin BL, Brautigan DL (1992) Regulation of protein serinethreonine phosphatase type-2A by tyrosine phosphorylation. Science 257: $1261-1264$

Chen P, Levis M, Brown P, Kim KT, Allebach J, Small D (2005a) FLT3/ITD mutation signaling includes suppression of SHP-1. J Biol Chem 280: $5361-5369$

Chen W, Arroyo JD, Timmons JC, Possemato R, Hahn WC (2005b) Cancerassociated PP2A Aalpha subunits induce functional haploinsufficiency and tumorigenicity. Cancer Res 65: 8183-8192

Colella S, Ohgaki H, Ruediger R, Yang F, Nakamura M, Fujisawa H, Kleihues P, Walter G (2001) Reduced expression of the Aalpha subunit of protein phosphatase $2 \mathrm{~A}$ in human gliomas in the absence of mutations in the Aalpha and Abeta subunit genes. Int J Cancer 93: 798-804

Copland M, Hamilton A, Elrick LJ, Baird JW, Allan EK, Jordanides N, Barow M, Mountford JC, Holyoake TL (2006) Dasatinib (BMS354825) targets an earlier progenitor population than imatinib in primary CML, but does not eliminate the quiescent fraction. Blood 107: $4532-4539$

Dai Y, Rahmani M, Corey SJ, Dent P, Grant S (2004) A Bcr/Ablindependent, Lyn-dependent form of imatinib mesylate (STI-571) 
resistance is associated with altered expression of Bcl-2. J Biol Chem 279: $34227-34239$

Deininger M, Buchdunger E, Druker BJ (2005a) The development of imatinib as a therapeutic agent for chronic myeloid leukemia. Blood 105: $2640-2653$

Deininger MWN, Bradeen H, Jia T, O’Hare T, Willis SG, Lee F, BJ D (2005b) Comparison of imatinib, AMN107 and dasatinib in an accelerated cell-based mutagenesis screen. Blood 106: 691

Donato NJ, Wu JY, Stapley J, Gallick G, Lin H, Arlinghaus R, Talpaz M (2003) BCR-ABL independence and LYN kinase overexpression in chronic myelogenous leukemia cells selected for resistance to STI571. Blood 101: $690-698$

Druker BJ, Tamura S, Buchdunger E, Ohno S, Segal GM, Fanning S, Zimmermann J, Lydon NB (1996) Effects of a selective inhibitor of the Abl tyrosine kinase on the growth of Bcr-Abl positive cells. Nat Med 2: $561-566$

Elmaagacli AH, Beelen DW, Opalka B, Seeber S, Schaefer UW (2000) The amount of BCR-ABL fusion transcripts detected by the real-time quantitative polymerase chain reaction method in patients with Philadelphia chromosome positive chronic myeloid leukemia correlates with the disease stage. Ann Hematol 79: 424-431

Fan Z, Beresford PJ, Oh DY, Zhang D, Lieberman J (2003) Tumor suppressor NM23-H1 is a granzyme A-activated DNase during CTLmediated apoptosis, and the nucleosome assembly protein SET is its inhibitor. Cell 112: $659-672$

Feschenko MS, Stevenson E, Nairn AC, Sweadner KJ (2002) A novel cAMP stimulated pathway in protein phosphatase $2 \mathrm{~A}$ activation. $J$ Pharmacol Exp Ther 302: $111-118$

Fornerod M, Boer J, van Baal S, Jaegle M, von Lindern M, Murti KG, Davis D, Bonten J, Buijs A, Grosveld G (1995) Relocation of the carboxyterminal part of CAN from the nuclear envelope to the nucleus as a result of leukemia-specific chromosome rearrangements. Oncogene 10: $1739-1748$

Francia G, Poulsom R, Hanby AM, Mitchell SD, Williams G, McKee P, Hart IR (1999) Identification by differential display of a protein phosphatase$2 \mathrm{~A}$ regulatory subunit preferentially expressed in malignant melanoma cells. Int J Cancer 82: 709-713

Guerzoni C, Bardini M, Mariani SA, Ferrari-Amorotti G, Neviani P, Panno ML, Zhang Y, Martinez R, Perrotti D, Calabretta B (2006) Inducible activation of $\mathrm{C} / \mathrm{EBP}\{$ beta\}, a gene negatively regulated by $\mathrm{BCR} / \mathrm{ABL}$, inhibits proliferation and promotes differentiation of BCR/ABL-expressing cells. Blood 107: 4080-4089

Hughes TP, Kaeda J, Branford S, Rudzki Z, Hochhaus A, Hensley ML, Gathmann I, Bolton AE, van Hoomissen IC, Goldman JM, Radich JP (2003) Frequency of major molecular responses to imatinib or interferon alfa plus cytarabine in newly diagnosed chronic myeloid leukemia. N Engl J Med 349: 1423 - 1432

Hunter T (1995) Protein kinases and phosphatases: the yin and yang of protein phosphorylation and signaling. Cell 80: 225-236

Iervolino A, Santilli G, Trotta R, Guerzoni C, Cesi V, Bergamaschi A, Gambacorti-Passerini C, Calabretta B, Perrotti D (2002) hnRNP A1 nucleocytoplasmic shuttling activity is required for normal myelopoiesis and BCR/ABL leukemogenesis. Mol Cell Biol 22: 2255-2266

Jamieson CH, Ailles LE, Dylla SJ, Muijtjens M, Jones C, Zehnder JL, Gotlib J, Li K, Manz MG, Keating A, Sawyers CL, Weissman IL (2004) Granulocyte-macrophage progenitors as candidate leukemic stem cells in blast-crisis CML. $N$ Engl J Med 351: 657-667

Janssens V, Goris J (2001) Protein phosphatase 2A: a highly regulated family of serine/threonine phosphatases implicated in cell growth and signalling. Biochem J 353: $417-439$

Janssens V, Goris J, Van Hoof C (2005) PP2A: the expected tumor suppressor. Curr Opin Genet Dev 15: 34-41

Johansson B, Fioretos T, Mitelman F (2002) Cytogenetic and molecular genetic evolution of chronic myeloid leukemia. Acta Haematol 107: $76-94$

Kamibayashi C, Lickteig RL, Estes R, Walter G, Mumby MC (1992) Expression of the A subunit of protein phosphatase $2 \mathrm{~A}$ and characterization of its interactions with the catalytic and regulatory subunits. J Biol Chem 267: 21864-21872

Kikura M, Morita K, Sato S (2004) Pharmacokinetics and a simulation model of colforsin daropate, new forskolin derivative inotropic vasodilator, in patients undergoing coronary artery bypass grafting. Pharmacol Res 49: 275-281

LaMontagne KR, Jr, Hannon G, Tonks NK (1998) Protein tyrosine phosphatase PTP1B suppresses p210 bcr-abl-induced transformation of rat-1 fibroblasts and promotes differentiation of K562 cells. Proc Natl Acad Sci USA 95: 14094-14099

Laneuville P, Sun G, Timm M, Vekemans M (1992) Clonal evolution in a myeloid cell line transformed to interleukin-3 independent growth by retroviral transduction and expression of p210bcr/abl. Blood 80: $1788-1797$

Li M, Makkinje A, Damuni Z (1996) The myeloid leukemia-associated protein SET is a potent inhibitor of protein phosphatase $2 \mathrm{~A}$. J Biol Chem 271: $11059-11062$

Li X, Yost HJ, Virshup DM, Seeling JM (2001) Protein phosphatase 2A and its B56 regulatory subunit inhibit Wnt signaling in Xenopus. EMBO J 20: $4122-4131$

Liedtke M, Pandey P, Kumar S, Kharbanda S, Kufe D (1998) Regulation of Bcr-Abl-induced SAP kinase activity and transformation by the SHPTP1 protein tyrosine phosphatase. Oncogene 17: 1889-1892

Lim YM, Wong S, Lau G, Witte ON, Colicelli J (2000) BCR/ABL inhibition by an escort/phosphatase fusion protein. Proc Natl Acad Sci USA 97: $12233-12238$

Martens E, Stevens I, Janssens V, Vermeesch J, Gotz J, Goris J, Van Hoof C (2004) Genomic organisation, chromosomal localisation tissue distribution and developmental regulation of the PR61/B' regulatory subunits of protein phosphatase 2A in mice. $J$ Mol Biol 336: $971-986$

Melo JV, Deininger MW (2004) Biology of chronic myelogenous leukemiasignaling pathways of initiation and transformation. Hematol Oncol Clin N Am 18: 545 - 568 (vii-viii)

Moon EY, Lerner A (2003) PDE4 inhibitors activate a mitochondrial apoptotic pathway in chronic lymphocytic leukemia cells that is regulated by protein phosphatase 2A. Blood 101: $4122-4130$

Neviani P, Santhanam R, Trotta R, Notari M, Blaser BW, Liu S, Mao H, Chang JS, Galietta A, Uttam A, Roy DC, Valtieri M, Bruner-Klisovic R, Caligiuri MA, Bloomfield CD, Marcucci G, Perrotti D (2005) The tumor suppressor PP2A is functionally inactivated in blast crisis CML through the inhibitory activity of the BCR/ABL-regulated SET protein. Cancer Cell 8: $355-368$

Notari M, Neviani P, Santhanam R, Blaser BW, Chang JS, Galietta A, Willis AE, Roy DC, Caligiuri MA, Marcucci G, Perrotti D (2006) A MAPK/ HNRPK pathway controls BCR/ABL oncogenic potential by regulating MYC mRNA translation. Blood 107: 2507-2516

O'Hare T, Walters DK, Stoffregen EP, Jia T, Manley PW, Mestan J, CowanJacob SW, Lee FY, Heinrich MC, Deininger MW, Druker BJ (2005) In vitro activity of Bcr-Abl inhibitors AMN107 and BMS-354825 against clinically relevant imatinib-resistant Abl kinase domain mutants. Cancer Res 65: $4500-4505$

Ostman A, Hellberg C, Bohmer FD (2006) Protein-tyrosine phosphatases and cancer. Nat Rev Cancer 6: $307-320$

Parsons R (1998) Phosphatases and tumorigenesis. Curr Opin Oncol 10: $88-91$

Perrotti D, Bonatti S, Trotta R, Martinez R, Skorski T, Salomoni P, Grassilli E, Lozzo RV, Cooper DR, Calabretta B (1998) TLS/FUS, a pro-oncogene involved in multiple chromosomal translocations, is a novel regulator of $\mathrm{BCR} / \mathrm{ABL}-$ mediated leukemogenesis. $E M B O \mathrm{~J} 17$ $4442-4455$

Perrotti D, Cesi V, Trotta R, Guerzoni C, Santilli G, Campbell K, Iervolino A, Condorelli F, Gambacorti-Passerini C, Caligiuri MA, Calabretta B (2002) BCR-ABL suppresses C/EBPalpha expression through inhibitory action of hnRNP E2. Nat Genet 30: $48-58$

Perrotti D, Turturro F, Neviani P (2005) BCR/ABL, mRNA translation and apoptosis. Cell Death Differ 12: $534-540$

Roy L, Guilhot J, Krahnke T, Guerci-Bresler A, Druker BJ, Larson RA, O'Brien S G, So C, Massimini G, Guilhot F (2006) Survival advantage from Imatinib compared to the combination Interferon-\{alpha\} plus Cytarabine in chronic phase CML: historical comparison between two phase III trials. Blood 2006 Apr20 [Epub ahead of Print]

Schonthal AH (2001) Role of serine/threonine protein phosphatase $2 \mathrm{~A}$ in cancer. Cancer Lett 170: $1-13$

Schultheis B, Szydlo R, Mahon FX, Apperley JF, Melo JV (2005) Analysis of total phosphotyrosine levels in CD34+ cells from CML patients to predict the response to imatinib mesylate treatment. Blood 105: 4893-4894

Seamon K, Daly JW (1981) Activation of adenylate cyclase by the diterpene forskolin does not require the guanine nucleotide regulatory protein. J Biol Chem 256: 9799-9801

Seeling JM, Miller JR, Gil R, Moon RT, White R, Virshup DM (1999) Regulation of beta-catenin signaling by the B56 subunit of protein phosphatase 2A. Science 283: 2089-2091 
Shah NP, Sawyers CL (2003) Mechanisms of resistance to STI571 in Philadelphia chromosome-associated leukemias. Oncogene 22: $7389-7395$

Skorski T (2002) BCR/ABL regulates response to DNA damage: the role in resistance to genotoxic treatment and in genomic instability. Oncogene 21: $8591-8604$

Sontag E (2001) Protein phosphatase 2A: the Trojan Horse of cellular signaling. Cell Signal 13: 7-16

Soverini S, Martinelli G, Rosti G, Bassi S, Amabile M, Poerio A, Giannini B, Trabacchi E, Castagnetti F, Testoni N, Luatti S, de Vivo A, Cilloni D, Izzo B, Fava M, Abruzzese E, Alberti D, Pane F, Saglio G, Baccarani M (2005) $\mathrm{ABL}$ mutations in late chronic phase chronic myeloid leukemia patients with up-front cytogenetic resistance to imatinib are associated with a greater likelihood of progression to blast crisis and shorter survival: a study by the GIMEMA Working Party on Chronic Myeloid Leukemia. J Clin Oncol 23: 4100-4109

Suzuki K, Takahashi K (2003) Reduced expression of the regulatory A subunit of serine/threonine protein phosphatase $2 \mathrm{~A}$ in human breast cancer MCF-7 cells. Int J Oncol 23: $1263-1268$

Talpaz M, Shah NP, Kantarjian H, Donato N, Nicoll J, Paquette R, Cortes J, O'Brien S, Nicaise C, Bleickardt E, Blackwood-Chirchir MA, Iyer V, Chen TT, Huang F, Decillis AP, Sawyers CL (2006) Dasatinib in imatinibresistant Philadelphia chromosome-positive leukemias. $N$ Engl J Med 354: 2531 - 2541

Tenenbaum SA, Lager PJ, Carson CC, Keene JD (2002) Ribonomics: identifying mRNA subsets in mRNP complexes using antibodies to RNAbinding proteins and genomic arrays. Methods 26: $191-198$

Trotta R, Vignudelli T, Candini O, Intine RV, Pecorari L, Guerzoni C, Santilli G, Byrom MW, Goldoni S, Ford LP, Caligiuri MA, Maraia RJ, Perrotti D, Calabretta B (2003) BCR/ABL activates mdm2 mRNA translation via the La antigen. Cancer Cell 3: $145-160$

Van Hoof C, Goris J (2004) PP2A fulfills its promises as tumor suppressor: which subunits are important? Cancer Cell 5: 105-106
Vera J, Jaumot M, Estanyol JM, Brun S, Agell N, Bachs O (2006) Heterogeneous nuclear ribonucleoprotein A2 is a SET-binding protein and a PP2A inhibitor. Oncogene 25: 260-270

Wajima Z, Shiga T, Yoshikawa T, Ogura A, Imanaga K, Inoue T, Ogawa R (2003) Effect of prophylactic bronchodilator treatment with intravenous colforsin daropate, a water-soluble forskolin derivative, on airway resistance after tracheal intubation. Anesthesiology 99: 18-26

Wang SS, Esplin ED, Li JL, Huang L, Gazdar A, Minna J, Evans GA (1998) Alterations of the PPP2R1B gene in human lung and colon cancer. Science 282: 284-287

Wera S, Fernandez A, Lamb NJ, Turowski P, Hemmings-Mieszczak M, Mayer-Jaekel RE, Hemmings BA (1995) Deregulation of translational control of the $65-\mathrm{kDa}$ regulatory subunit (PR65 alpha) of protein phosphatase 2A leads to multinucleated cells. J Biol Chem 270: $21374-21381$

Wu C, Guan Q, Wang Y, Zhao ZJ, Zhou GW (2003) SHP-1 suppresses cancer cell growth by promoting degradation of JAK kinases. J Cell Biochem 90: 1026-1037

Xie S, Lin H, Sun T, Arlinghaus RB (2002) Jak2 is involved in c-Myc induction by Bcr-Abl. Oncogene 21: $7137-7146$

Yeh E, Cunningham M, Arnold H, Chasse D, Monteith T, Ivaldi G, Hahn WC, Stukenberg PT, Shenolikar S, Uchida T, Counter CM, Nevins JR, Means AR, Sears R (2004) A signalling pathway controlling c-Myc degradation that impacts oncogenic transformation of human cells. Nat Cell Biol 6: 308-318

Yokoyama N, Miller WT (2001) Inhibition of Src by direct interaction with protein phosphatase 2A. FEBS Lett 505: $460-464$

Yokoyama N, Reich NC, Miller WT (2001) Involvement of protein phosphatase $2 \mathrm{~A}$ in the interleukin-3-stimulated Jak2-Stat5 signaling pathway. I Interferon Cytokine Res 21: 369-378

Yuan H, Veldman T, Rundell K, Schlegel R (2002) Simian virus 40 small tumor antigen activates AKT and telomerase and induces anchorageindependent growth of human epithelial cells. J Virol 76: 10685-10691 